\title{
Design of Decision Support System for Soil Testing and Formula Fertilization based on the Intelligent Agriculture Yue $\mathrm{Q}^{1, \mathrm{a}}$, Yueying LENG ${ }^{2, \mathrm{~b}}$, Min WANG ${ }^{3, \mathrm{c}}$, Yinan $\mathrm{HU}^{4, \mathrm{~d}}$, YaneBai* \\ ${ }^{1}$ College of management, Jilin University, Changchun, 130022, China \\ ${ }^{2}$ College of management, Jilin University, Changchun, 130022, China \\ ${ }^{3}$ College of management, Jilin University, Changchun, 130022, China \\ ${ }^{4}$ Guangxi Coast Guard First Detachment, Beihai, 536000,China \\ *Master, Lecturer teaching Computer Base in School, Changchun University \\ of Science and Technology,Changchun,130022,China \\ aemail: qy765867465@163.com, bemail:949898533@qq.com

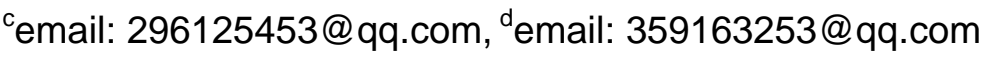 \\ *email:bye1023@126.com
}

Keywords: Intelligent Agriculture; Soil Testing And Formula Fertilization; Decision Support System

\begin{abstract}
This paper citation network analysis scientific knowledge mapping tool, which called CiteSpace information visualization software rendering, obtained China's development of intelligent agriculture, hot topics and research trends in recent years, at the same time design a system based on Intelligent fertilization which is superior to the traditional agriculture modernization fertilization decision support system for networking, wireless sensors. The traditional manual operation of intelligent control and other modern information technology to replace the cumbersome, bring great convenience for crop fertilization.
\end{abstract}

\section{Introduction}

Intelligent agriculture is the most efficient use of agricultural resources, reduce agricultural cost and energy consumption, reduce agricultural ecological damage to the environment and achieve the overall optimization of agricultural system as the goal, to the agricultural industry, for the features of the whole process of intelligent ubiquitous, with comprehensive perception, reliable transmission and intelligent processing etc. network technology and means to automated production, optimal control, intelligent management system of logistics and electronic trading as the main mode of production of high yield, high efficiency, low consumption, high quality, ecological and safety for the development of modern agriculture and patterns[1].

The research of intelligent agriculture is the community in recent years, especially the focus of agricultural research and academic researchers, by Professor Chen Chaomei's Rashel of the United States University of Java development based on CiteSpace program is mainly used in the scientific literature data measurement and analysis[2], identification and display the new trend of scientific development and new developments, and in the analysis and visualization of CO citation network with accurate, convenient and efficient characteristics.

Specifically, the study on intelligent agriculture related literature as the research object, the target in the field of literature cited and citation descriptive statistics and data mining using CiteSpace visualization software[3], will draw out the knowledge base of research in the field of smart agriculture, intelligent agriculture and the hot spot in the fields of evolution path, research content analysis. I study in Intelligent Agriculture began to enter the peak in 2012, the main force research focuses on Colleges and universities and all kinds of agricultural scientific research institute, a number of influential high cited documents, mainly related to automation technology, computer software and computer application, agricultural engineering and other disciplines, but research 
cooperation needs to be strengthened. Through scientific knowledge mapping analysis. Dig out the hot topic in the field of intelligent agriculture, such as networking, wireless sensor network, ZigBee communication technology, intelligent control, agricultural modernization On behalf of the agricultural information and so on, these research level has been widely concerned. Agricultural modernization, agricultural networking, intelligent agriculture, is becoming a new research frontier, is likely to become the next stage of research hot spots.

Intelligent agriculture is the inevitable trend of the development of modern agriculture in the world, the application of information technology in agriculture can be quantitative timing according to the change of space to complete the operation and management of agricultural system[4], in other words, is based on the crops grown in the soil condition to carry on the reasonable allocation, which can not only identify the cultivation of crops and soil properties and productivity spatial variability can determine the direction of production, to adjust and optimize the formula according to the situation analysis, systematic diagnosis, scientific management[5], improve the utilization efficiency of soil, do much less, improve resource utilization, improve the bad environment, so as to maximize the social benefit and economic value[6].

\section{Design of the Decision Support System}

Fertilization from fertilization and fertilization. Fertilization is based on nutrient content and uptake of different crops to determine a method of fertilization in soil, soil testing and fertilizer itself including fertilizer content, and get the "formula" to be more precise, more objective; but also the formula fertilization determination of soil nutrients, but also to a large number of field tests, get the function of fertilizer effect, this is not the content of fertilization. Fertilization and fertilization is a common purpose, just focus on the surface is different, so it is generally called fertilization[7]. The decision support system is based on management science, system science and behavior science based on mathematics, computer technology and information technology as a means for semi-structured decision problems, computer information system to assist decision activities. It helps decision-makers to use all kinds of decision models and data, through the man-machine interaction, give full play to the initiative of the people, to solve practical problems[8]. Its main features are: assist decision-makers, rather than replace the decision-maker; for the treatment of various semi structured and structured decision problems; has a friendly man-machine interface; the changing of external environment and decision making method has high flexibility and adaptability; decision the purpose is to improve the effectiveness of decision conclusion[9].

The basic framework of the system is shown in the following figure:




The overall structural design of the system is shown below :

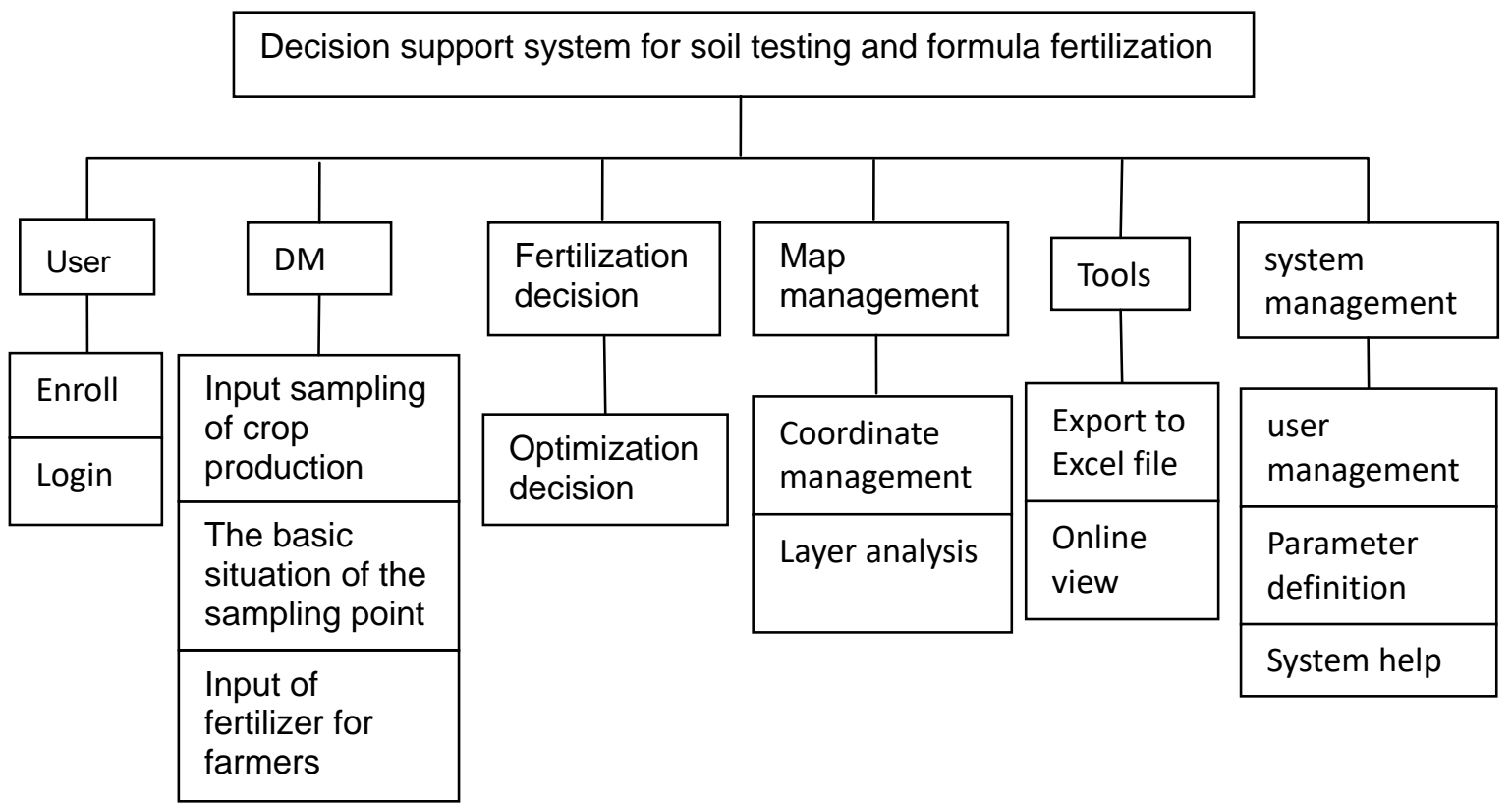

The overall function of the system is shown below:

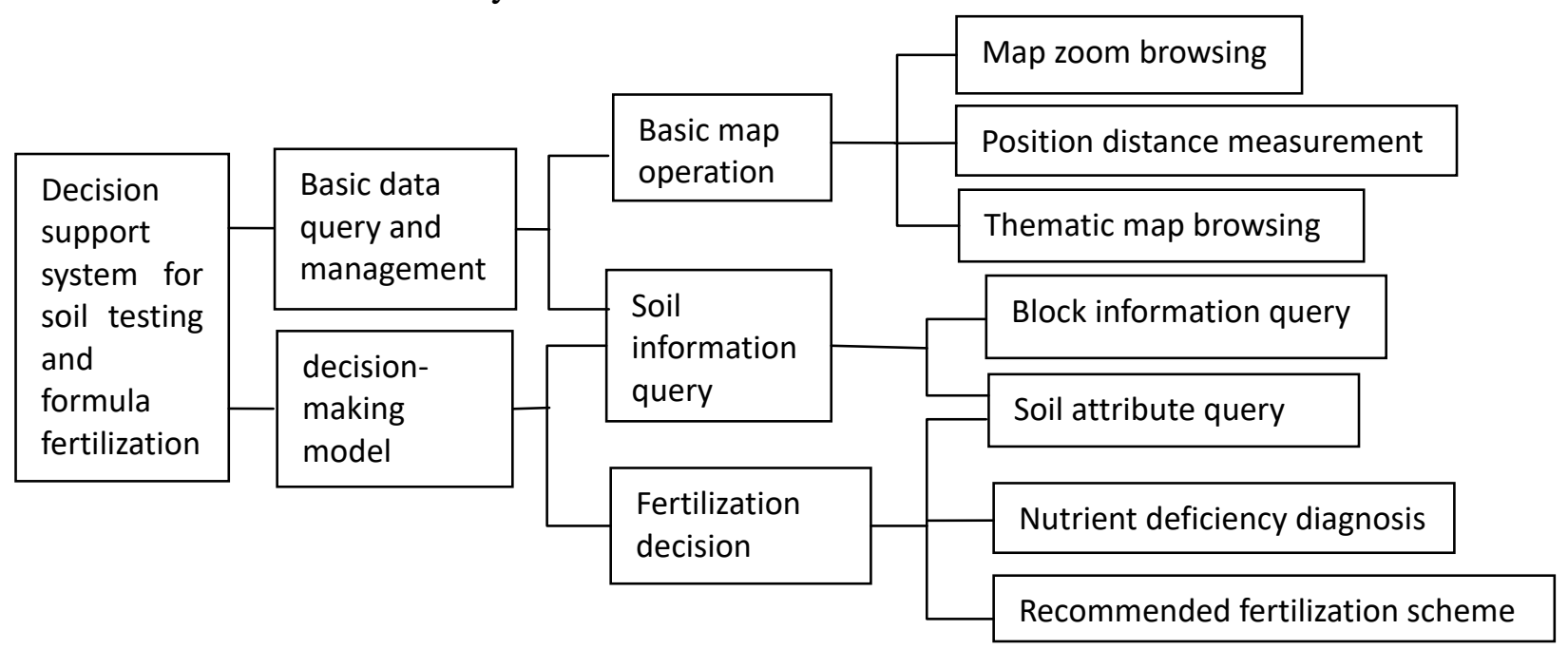

\section{System optimization design}

The system uses wireless sensor technology to collect crop soil data, instead of tedious and accurate rate of manual collection work, and the establishment of the system database to store the data collected in order to prepare for use. The soil nutrient database includes spatial data and attribute data, Supplementary information database contains information about the use of fertilizers and agricultural production information table and so on. Wireless sensor monitoring system functions as follows: 


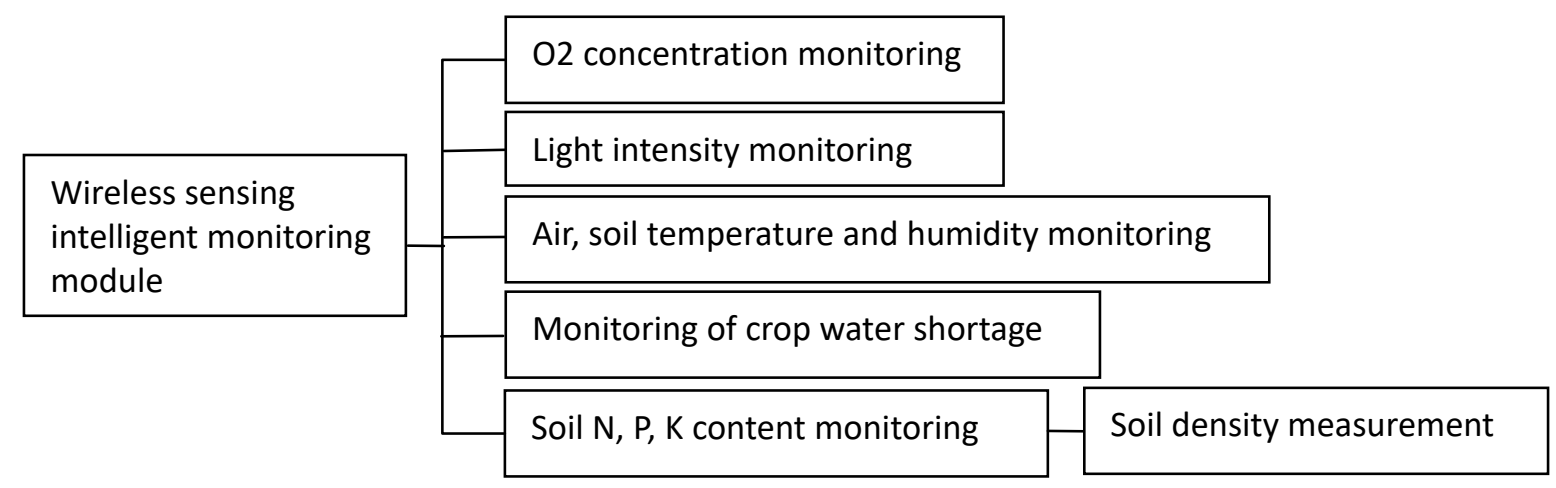

\section{Soil fertilization decision model}

Using wireless sensor data collected from the field and local soil and fertilizer station provides data for the sample information, using BP neural network model of 3 layer structure[10] and accurate analysis of soil, nitrogen, phosphorus and potassium fertilizer amount and the actual amount of the estimated error ratio, the decision results feedback to the user, to achieve the purpose of precise fertilization.

Back Propagation neural network, which is the learning process of back propagation error back propagation algorithm, consists of two processes: the forward propagation of information and the back propagation of error. When the actual output is not in conformity with the expected output, the reverse propagation phase of the error is entered. The error is corrected by the output layer, and the weight of each layer is corrected by the error gradient descent method[11]. Information forward and back propagation process again and again, is a process of weights adjustment, the process has been carried out to reduce the error of the network output to an acceptable level.

Tab. 1 Soil Fertility matrix of neural network after weighting

\begin{tabular}{ccccccccc}
\hline \multirow{2}{*}{ Point } & \multicolumn{9}{c}{ M1 } & \multicolumn{2}{c}{ M2 } \\
\cline { 2 - 9 } & $\mathrm{pH}$ & $\begin{array}{c}\text { Salt } \\
\text { content }\end{array}$ & $\begin{array}{c}\text { Organic } \\
\text { matter }\end{array}$ & $\begin{array}{c}\text { Total } \\
\text { nitrogen }\end{array}$ & $\begin{array}{c}\text { Texture } \\
\text { configuration }\end{array}$ & CEC & Capacity \\
\hline 1 & -0.5645 & -0.4326 & 0.1258 & 0.5427 & 0.8513 & -0.0152 & 0.8255 & 0.5913 \\
2 & 0.0127 & 0.0359 & -0.0871 & 0.0263 & 0.3693 & -0.4258 & 1.0353 & -0.4113 \\
3 & 0.6628 & 0.9120 & -0.6912 & 0.4293 & -0.8064 & 0.4230 & -0.6424 & -0.8660 \\
4 & 0.2702 & -0.3126 & -0.4321 & 0.3753 & -0.8022 & 0.6852 & -0.1255 & 0.5822 \\
5 & -0.5663 & -0.8026 & -0.9503 & -0.7525 & -0.5265 & 0.3323 & -0.3022 & -0.8252 \\
6 & -0.2692 & 0.3522 & -1.0653 & 0.8537 & -0.7137 & 0.7352 & 0.6404 & -0.3326 \\
7 & 0.1998 & -0.4891 & 0.7402 & 0.6204 & -0.2012 & 0.3893 & -0.94210 & -0.5128 \\
8 & 0.8905 & 0.3596 & -0.5804 & 0.3297 & 0.5605 & 0.1904 & 0.6288 & 0.4005 \\
9 & -0.5024 & -0.4325 & 0.5763 & 0.2108 & -0.3396 & 0.9124 & -1.0156 & 0.4896 \\
10 & 0.1398 & 0.2635 & 0.4895 & -0.5144 & -0.8796 & -0.9855 & -1.1257 & -0.7498 \\
\hline
\end{tabular}

Tab. 2 Error calculation of soil $\mathrm{N}$ fertilizer model

\begin{tabular}{cccc}
\hline \multirow{2}{*}{ Maize unit yield } & Actual nitrogen fertilizer & $\begin{array}{c}\text { Network calculation of nitrogen } \\
\text { fertilizer }\end{array}$ & Error/\% \\
\hline 4180.13 & 0 & $0.6123 \times 10^{-9}$ & 0 \\
4325.26 & 85.5 & 85.2952 & 0.22 \\
4881.23 & 200 & 200.0000 & 0 \\
3654.41 & 300 & 299.9565 & 0.15 \\
3347.38 & 400 & 400.0000 & 0 \\
\hline
\end{tabular}

Weight is the relative importance of a certain index in the overall evaluation. The neural network function[12] and error calculation model to test the indexes of soil fertility, soil parameter weights. Table 1 for the weighted neural network soil fertility matrix, M1 is the input layer and the hidden layer between the weights, M2 is the hidden layer and the weight of the output layer. 
After comparing the weight of soil fertility parameters, the crop yield data were compared, and the results were shown in table 2.

The results has shown that the error between the neural network analysis of fertilization and actual fertilization[13] was less than $0.25 \%$, the soil fertility parameters calculated the weight function analysis using statistical neural network, according to the requirements of crop yield, establish the fertilization decision-making model of fertilizer will need the amount of feedback to the user.

\section{Application Area}

Based on the idea of intelligent agriculture and the existing fertilization decision system analysis and optimization design of the basic framework of decision support system for fertilization of soil testing and intelligent agriculture based on the overall structure and overall function, the design accuracy part can meet the basic fertilizer formulation, for the user through the network, computer terminal, mobile terminal to provide more convenient, more effective, more efficient, crop fertilization strategy more practical application value.

Also, the fertilization decision support system function is clear, easy to understand; simple operation interface, easy to use, suitable for the majority of users, especially the computer equipment of the intelligent network, mobile devices, not very understanding of the farmers, the same can get started quickly.

\section{Conclusion}

The design and development of such a precise, practical fertilization decision support system, which can reduce the waste of fertilizer, and can be reduced to the minimum amount of residual soil fertilizer, improve agricultural production, improve the quality of agricultural products, the better the level of agricultural China faster development. Therefore, China is still the need to strengthen the development of agricultural technology, not only can be designed to the system, but also can be developed to meet the needs of development in various provinces and cities of our country agriculture needs, follow the world agricultural development pace.

\section{References}

[1] Liu Jing, Xing Li. The application of the Internet of things technology in intelligent agriculture [J]. vocational education research, 6 monthly in 2014: 45-47,57.

[2] Shi Xiaocen, Li Manli. Hot and trends of international MOOC research. Open education research, 20162 monthly (22):90-99.

[3] Zhou Xiao, Huang Guobin. Research on the comparison and data preprocessing of scientific measurement and visualization software. Library and information work, 201312 monthly (57):64-72.

[4] Hou Baoming, E Xu. Intelligent agriculture based on Internet of things [J]. computer technology and development, 20149 monthly: 164-167.

[5] Huang Kun. Xinyang agricultural decision support system structure and function design [J]. China western science and technology, 20103 monthly (9):29-31.

[6] Wang Peng, Ma Youhua, et al. Development and application of soil testing and formula fertilization decision system in County of Anhui province [J]. Chinese agricultural bulletin, 2009,25 (04):283-287.

[7] High Xiangzhao. Fertilization technology [M]. Chinese Agriculture Press, 2005.

[8] Han Xuehong. A review of research on agricultural intelligent decision support system based on 
[J]. GIS science and technology guide, the first 04 (on):25-26. 2010.

[9] Mou Yingying. Research and development of WebGIS Xinjiang fruit fertilization decision system platform -- Taking Korla as an example based on pear [D]. Xinjiang Agricultural University, 2015.

[10] Alexis S, Garcia-Montero L G, Hernandez A J, et al. Soil fertility and GIS raster models for tropical agroforestry planning in economically depressed and contaminated Caribbean areas (coffee and kidney bean plantations) [J]. Agroforestry Systems, 2010, 79(3): 381 391.

[11] Li Shiyong. Fuzzy control. Neural network and intelligent control theory [M]. Harbin: Harbin Institute of Technology press, 1996.

[12] Breiman L. Bagging predictors [J]. Machine Learning, 1996, 24(2): 123 140.

[13] Reddy K C, Ahmed S R. Soil test based fertilizer recommendation for maize grown in Inceptisols of Jagtiyal in Andhra Pradesh [J]. Journal of the Indian Society of Soil Science, 2000, 48(1): 84 89. 